\title{
Cardiac and vascular complications of Behçet disease in the Tunisian context: clinical characteristics and predictive factors
}

\author{
Melek Kechida ${ }^{{ }^{*}}$, Sana Salah², Rim Kahloun ${ }^{3}$, Rim Klii ${ }^{1}$, Sonia Hammami ${ }^{1}$ and Ines Khochtali ${ }^{1}$
}

\begin{abstract}
Background: Cardiac and vascular involvement in Behçet disease (BD), also referred as vasculo BD, is frequent. We aimed to describe clinical characteristics, predictive factors and management of vasculo BD in the Tunisian context.

Methods: We retrospectively studied 213 records of all BD patients followed between January 2004 and May 2016 in the Internal Medicine Department and who fulfilled the ISGBD criteria. We described first clinical features of BD with cardiac and vascular involvement then predictive factors were studied in univariate then multivariate analysis.

Results: Among the 213 patients, 64 (30\%) were diagnosed as having vasculo BD. The mean age at diagnosis was 31.5 years. About $81.25 \%$ of them were males and $18.75 \%$ females. Vascular involvement associated or not with cardiac involvement was found in 64 patients (30\%). Deep venous thromboses are most common (62.5\%) compared with superficial ones (23.4\%), pulmonary arterial thrombosis (14.1\%) or aneurysms (9.4\%). Cardiac involvement is ranging from pericarditis (1.6\%) to intra cardiac thrombosis (3.1\%) and myocardial infarction (1.6\%). Predictive factors associated with cardiac and vascular involvement in $\mathrm{BD}$ are male gender $(\mathrm{OR}=3.043,95 \%$ $\mathrm{Cl}=1.436-6.447, p=0.004)$, erythema nodosum $(\mathrm{OR}=4.134,95 \% \mathrm{Cl}=1.541-11.091, p=0.005)$ and neurologic involvement $(\mathrm{OR}=2.46,95 \% \mathrm{Cl}=1.02-5.89, p=0.043)$.
\end{abstract}

Conclusion: Cardiac and vascular involvement in BD is frequent in the Tunisian context with a broad spectrum of manifestations ranging from vascular involvement to cardiac one. Male gender, patients with erythema nodosum or neurologic involvement are prone to develop cardiac or vascular features of BD needing therefore a close monitoring.

Keywords: Behcet syndrome, Cardiovascular system, Risk factors

\section{Background}

Behçet disease (BD) is a systemic vasculitis of unknown origin with a remitting and relapsing course. It is prevalent along the "silk road" extending from Japan to the Middle Eastern and the Mediterranean countries [1]. BD usually affects patients around the third or fourth decade of life [1]. Sex distribution is roughly equal with some particularities all over the world. In fact, BD would be more prevalent in males in some Middle Eastern and the Mediterranean countries and less frequent in females in Japan and Korea [1].

\footnotetext{
* Correspondence: kechida_mel_lek@hotmail.com

${ }^{1}$ Internal Medicine and Endocrinology Department, Fattouma Bourguiba

University Hospital, 1st June Avenue, 5000 Monastir, Tunisia

Full list of author information is available at the end of the article
}

BD is mainly characterized by recurrent oral and genital aphthosis associated with other cutaneous and ocular manifestations. It may also involve, in a lesser extent, the gastro intestinal tract, joints and the central nervous system. These clinical signs seem to vary in prevalence according to the ethnic groups and geographical regions.

Cardiac and vascular involvement, also referred as vasculo $\mathrm{BD}$, is frequent. It can reach $46 \%$ of patients according to the literature [2] affecting all sizes of arteries and veins as well as all the cardiac layers and accounting for the major cause of mortality.

As clinical signs are varying according to the ethnic groups and the geographical regions, and as data regarding prevalence and management of vasculo $\mathrm{BD}$ in the North African countries are lacking, we aimed in this

(C) The Author(s). 2018 Open Access This article is distributed under the terms of the Creative Commons Attribution 4.0 International License (http://creativecommons.org/licenses/by/4.0/), which permits unrestricted use, distribution, and 
work to describe clinical characteristics, predictive factors and management of cardiac and vascular involvement in BD in the Tunisian context.

\section{Methods}

We retrospectively studied records of Behçet Disease patients followed in Internal Medicine Department of Fattouma Bourguiba University Hospital between January 2004 and May 2016. All patients fulfilled the International Study Group for Behçet Disease criteria [2].

Patients with cardiac involvement are defined as having pericarditis and/or myocarditis and/or intra cardiac thrombosis and/or myocardial infarction associated or not to vascular involvement. Patients with vascular involvement are those having deep venous thrombosis and/or superficial venous thrombosis and/or pulmonary embolism and/or arterial aneurysm without cardiac involvement.

Cardiac and vascular involvement diagnosis was based on clinical examination and imaging techniques including Computed Tomography Angiography, Magnetic Resonance Angiography and Doppler ultrasound. Screening for cardiac and vascular involvement was performed in symptomatic patients only.

We described first clinical features of BD with cardiac and vascular involvement then a comparative study was performed between patients with (group 1) and without cardiac and/or vascular involvement (group2). Predictive factors of cardiac and/or vascular involvement were studied in univariate then multivariate analysis.

The $t$ test was used to analyze the continuous variables. The chi-square test was used to analyze the categorical variables. Multivariate analysis of variables significantly associated with cardiac and vascular involvement in univariate analysis was performed using binary logistic regression. Results are expressed as odds ratios (OR) with accompanying 95\% confidence interval $(95 \% \mathrm{CI})$. A $p$ value $<0.05$ was considered significant and if needed Fisher's exact test was used. Only relevant predictive factors highly associated with cardiac and vascular involvement were analyzed according to the goodness of fit of Hosmer-Lemeshow test. All data were assessed on computer using a SPSS 21.0 software package.

\section{Results}

Out of 213 BD patients studied, 145 (68.1\%) were males and $68(31.9 \%)$ were females. Sex ratio M/F was 2.13. Mean age at diagnosis was 30.6 years. Oral ulcers were found in 210 patients $(98.6 \%)$ at presentation occurring then in all patients during follow-up. Cutaneous manifestations were present in 190 patients (89.2\%). Pathergy test done in 174 patients was positive in 108 of cases $(62.06 \%)$. Clinical characteristics of the patients are reported in Table 1. HLA 51 done in 113 patients (53.05\%) was positive in 18 patients (15.92\%).

Among the 213 patients, 64 (30\%) were diagnosed as having vasculo $\mathrm{BD}$. The mean age at diagnosis was 31.5 years. About $81.25 \%$ of them were males and $18.75 \%$ were females.

Vascular involvement was found in 59 patients (27.7\%), isolated cardiac involvement in 2 patients $(0.9 \%)$ and the association of cardiac and vascular involvement was found in 3 patients (1.4\%).

Eight patients $(12.5 \%)$ had cardiac or vascular involvement as a first manifestation of the disease. Deep venous thrombosis were reported in 40 patients (62.5\%). Venous thrombosis occurred in more than one site in 3 cases (7.5\%).

Superficial venous thrombosis affected 15 patients (23.4\%). Arterial involvement was found in 16 patients (25.1\%) with pulmonary embolism in 9 patients (14.1\%), pulmonary aneurysm in 6 patients $(9.4 \%)$ and aorta aneurysm in 1 case (1.6\%). Cardiac involvement was found in 5 patients $(7.9 \%)$.

Cardiac and vascular involvement is detailed in Table 2.

Management of cardiac or vascular involvement in BD consisted in colchicine in all patients, corticotherapy in 22 patients (46\%) and immunosuppressors in 17 patients (26.6\%) which were Cyclophasphamide or Azathioprine. Oral anticoagulation was associated in 44 patients (72.1\%). Arterial Embolisation was performed in 2 patients (3.3\%).

Table 1 clinical features of patients with Beçet Disease syndrome

\begin{tabular}{ll}
\hline Clinical features & Results \\
\hline Sex & \\
- Male (n) (\%) & $145(68.1)$ \\
- Female (n) (\%) & $68(31.9)$ \\
Age at diagnosis (years) & 30.6 \\
Family history of BD (n) (\%) & $27(13.8)$ \\
Oral ulcers (n) (\%) & $210(98.6)$ \\
Genital ulceration (n) (\%) & $178(83.6)$ \\
Pseudofolliculitis (n) (\%) & $169(79.3)$ \\
Erythema nodosum (n) (\%) & $21(9.99)$ \\
Positive pathergy reaction (n) (\%) & $108(62.06)$ \\
Joint involvement (n) (\%) & $94(44.3)$ \\
Ophthalmic involvement (n) (\%) & $67(31.6)$ \\
Neurological manifestations (n) (\%) & $26(12.3)$ \\
Cardiovascular complications (n) (\%) & $64(30)$ \\
Gastrointestinal involvement (n) (\%) & $1(0.5)$ \\
Orchitis (n) (\%) & $12(5.6)$ \\
\hline
\end{tabular}


Table 2 cardiovascular features in Behçet Disease patients

\begin{tabular}{ll}
\hline Cardiovascular features & Patients (n)(\%) \\
\hline Vascular involvement (n) (\%) & $73(34.27)$ \\
Deep venous thrombosis (n) (\%) & $40(62.5)$ \\
- Upper limb (n) (\%) & $8(12.5)$ \\
- Lower limb (n) (\%) & $16(25)$ \\
- Bilateral lower limb (n) (\%) & $3(4.7)$ \\
- Inferior vena cava (n) (\%) & $8(12.5)$ \\
- More than one site (n) (\%) & $3(4.7)$ \\
- Budd Chiari syndrome (n) (\%) & $1(1.55)$ \\
- Mesenteric vein (n) (\%) & $1(1.55)$ \\
Superficial venous thrombosis (n) (\%) & $15(23.4)$ \\
Pulmonary embolism (n) (\%) & $9(14.1)$ \\
Pulmonary arterial aneurysm (n) (\%) & $6(9.4)$ \\
Ascending aorta aneurysm (n) (\%) & $1(1.6)$ \\
Cardiac involvement (n) (\%) & $5(2.4)$ \\
- Pericarditis (n) (\%) & $1(1.6)$ \\
-Myocarditis (n) (\%) & $1(1.6)$ \\
- Intra cardiac thrombosis (n) (\%) & $2(3.1)$ \\
- Myocardial infarction (n) (\%) & $1(1.6)$ \\
\hline
\end{tabular}

Comparative study between patients with (group 1) and without cardiac or vascular involvement (group 2) revealed significant prevalence of males in group 1 $(81.3 \%$ vs $62.4 \%)(p=0.007)$, and increased frequency of patients with erythema nodosum (17.2\% vs $6.7 \%)$ $(p=0.019)$ and with orchitis $(10.9 \%$ vs $3.4 \%)(p=0.047)$ (Exact Fisher test) (Table 3).

Multivariable analysis performed on this model showed that predictive factors for cardiac or vascular involvement were male gender $(\mathrm{OR}=3.043,95 \% \mathrm{CI}=$ 1.436-6.447, $p=0.004)$, erythema nodosum $(\mathrm{OR}=4.134$, $95 \% \mathrm{CI}=1.541-11.091, \quad p=0.005)$ and neurologic involvement $(\mathrm{OR}=2.46,95 \% \mathrm{CI}=1.02-5.89, p=0.043)$ (Table 4).

\section{Discussion}

Cardiac and vascular involvement in BD is rarely reported in African countries. To the best of our knowledge, this study is the first to focus on cardiac and vascular spectrum in $\mathrm{BD}$ patients in a Tunisian cohort.

Cardiac and vascular involvement is frequent in our cohort, diagnosed in $30 \%$ of our patients. It is estimated to range from 7 to $46 \%$, [3] according to the published data, and to affect about $27 \%$ in the Tunisian multicenter study of 519 patients [4]. Predictive factors of cardiac and vascular involvement found in our cohort were male gender $(\mathrm{OR}=3.043,95 \% \mathrm{CI}=1.436-6.447, p=0.004)$, erythema nodosum $(\mathrm{OR}=4.134,95 \% \mathrm{CI}=1.541-11.091$, $p=0.005)$ and neurologic involvement $(\mathrm{OR}=2.46,95 \%$
Table 3 Comparison of clinical features in Behçet Disease patients with and without vascular involvement

\begin{tabular}{|c|c|c|c|}
\hline & $\begin{array}{l}\text { Patients with } \\
\text { cardiovascular } \\
\text { involvement } \\
\text { (group1) }(n=64)\end{array}$ & $\begin{array}{l}\text { Patients without } \\
\text { cardiovascular } \\
\text { involvement } \\
\text { (group 2) }(n=149)\end{array}$ & $P$ value \\
\hline \multicolumn{4}{|l|}{ Sex } \\
\hline - Males (n) (\%) & $52(81.3)$ & $93(62.4)$ & $0.007^{*}$ \\
\hline - Females (n) (\%) & 12(18.8) & $56(37.6)$ & \\
\hline Age (years) & 31.5 & 30.21 & 0.43 \\
\hline $\begin{array}{l}\text { Familiar history } \\
\text { of } \mathrm{BD}(\mathrm{n})(\%)\end{array}$ & $5(8.9)$ & $22(15.8)$ & 0.2 \\
\hline $\begin{array}{l}\text { Oral aphthosis } \\
\text { (n) (\%) }\end{array}$ & 63(98.4) & 147(98.7) & 0.9 \\
\hline $\begin{array}{l}\text { Genital } \\
\text { ulcerations (n) (\%) }\end{array}$ & 53(82.8) & 125(83.9) & 0.84 \\
\hline $\begin{array}{l}\text { Pseudofolliculitis } \\
\text { (n) (\%) }\end{array}$ & $54(84.4)$ & $115(77.2)$ & 0.23 \\
\hline $\begin{array}{l}\text { Erythema } \\
\text { nodosum (n) (\%) }\end{array}$ & $11(17.2)$ & $10(6.7)$ & $0.019 *$ \\
\hline $\begin{array}{l}\text { Ophthalmic } \\
\text { involvement } \\
\text { (n) (\%) }\end{array}$ & 20(31.3) & $47(31.5)$ & 0.96 \\
\hline $\begin{array}{l}\text { Neurological } \\
\text { involvement } \\
\text { (n) (\%) }\end{array}$ & $12(18.8)$ & $14(9.4)$ & 0.056 \\
\hline Orchitis (n) (\%) & $7(10.9)$ & $5(3.4)$ & $\begin{array}{l}\mathbf{0 . 0 4 7}^{*} \\
\text { (exact Fisher } \\
\text { test) }\end{array}$ \\
\hline
\end{tabular}

${ }^{*} p<0.05$

$\mathrm{CI}=1.02-5.89, p=0.043)$. All studies dealing with cardiac or vascular involvement in $\mathrm{BD}$ are unanimous on the fact that the frequency of these complications is higher in males [4-7]. Some authors found that eye involvement, genital ulcers and arthritis were less frequent in vasculo-BD patients [8], which was not the case in our study.

Cardiac or vascular complications revealed the disease in $12.5 \%$ of cases in our patients. In the study of Fei et al. [6], 27.5\% of patients presented with vascular involvement as the initial manifestation.

There is a broad spectrum of cardiac and vascular involvement in $\mathrm{BD}$ patients and we found that vascular manifestations are more frequent than cardiac ones.

Table 4 Predictive factors independently associated with cardiovascular involvement in patients with BD in multivariate analysis

\begin{tabular}{llll}
\hline Variable & Odds ratio & $95 \% \mathrm{Cl}$ & $p$ value \\
\hline Male gender & 3.043 & $1.436-6.447$ & $0.004^{*}$ \\
Erythema nodosum & 4.134 & $1.541-11.091$ & $0.005^{*}$ \\
Neurological involvement & 2.462 & $1.028-5.893$ & $0.043^{*}$ \\
\hline
\end{tabular}

Cl confidence interval; * $p<0.05$ 
Cardiac involvement is accounting for 1 to 6\% [5] and occurred in $2.4 \%$ of patients in our study. The main types of cardiac features are pericarditis, valvular insufficiency, intra cardiac thrombosis and myocardial infarction. Pericardial involvement has been reported as the most common manifestation in some series $[3,9]$. Clinical presentation may be acute pericarditis, recurrent pericarditis, constrictive pericarditis, hemorrhagic pericarditis tamponade or even asymptomatic pericardial effusion $[3,5]$. But unlike literature findings, pericarditis was not the first most frequent cardiac feature in our cohort $(1.6 \%)$, it was intra cardiac thrombosis $(3.1 \%$ of cases). This probably could be explained by the asymptomatic character of pericarditis which can be missed as echocardiography was not systematically done for all the patients. Intra cardiac thrombosis is generally considered one of the serious cardiac complications which may cause pulmonary embolism [3] like in one of our patients or cerebral emboli by passing through the patent foramen ovale. The right ventricle is usually involved, which was the case of all our patients [3]. But it has been demonstrated that the left ventricle can also be involved [10, 11].

Myocardial infarction diagnosed in one of our patients was caused by coronary aneurysm. Coronary lesions are usually proximal [5] and some of them may be asymptomatic [3]. Sinus Valsalva aneurysms may occur alone or with other sinus aneurysms and may lead to acute or chronic aortic failure [3].

We reported a rare case of myocarditis revealing BD which was diagnosed in a patient with fever and chest pain confirmed with MRI findings. Few data is found in this field, Geri et al. [5] reported only one case in a series of 52 European patients and two cases were reported in a Japanese autopsy series [12].

Vascular system involvement emerged in approximately 1.8 to $51.6 \%$ of BD patients affecting all sizes of arteries and veins and accounting for the major cause of mortality [6]. It was estimated at $34.27 \%$ in our study.

Vascular lesions mainly consist in venous and arterial thrombosis and various types of arterial aneurysms. Venous lesions were more common in our cohort reaching $85.9 \%$ in agreement of literature findings which demonstrated that venous lesions were more frequently affected than arterial lesions [6]. Venous involvement can affect lower extremities as well as upper limb. Others including inferior vena cava, Budd-Chiari syndrome (hepatic vein thrombosis) and mesenteric vein thrombosis are rarely seen [13].

Arterial involvement is less common than venous one [3]. It consists in thrombosis or aneurysms. Pulmonary embolism, although found in $14.1 \%$ in our study, is thought to be rare in the literature given that the thrombi in the inflamed veins of the lower extremities are strongly adherent. [6, 14]. Aneurysms are considered to be the most severe complications given the high risk of rupture [6]. They mainly affect pulmonary arteries (9.4\% in our cohort) but can be located in systemic circulation. We described the first case of ascending aortic aneurysm associated with deep vein thrombosis revealing BD. Few articles reported cases of Hughes Stovin Syndrome revealing BD. It's a rare entity defined as thrombophlebitis associated with pulmonary aneurysms [15]. Few cases were reported with associated aneurysm of the systemic circulation such bronchial, external carotid, iliac artery aneurysm and left hepatic artery [16] but no association with ascending aorta aneurysm was reported.

Treatment of BD is still based on a low level of evidence $[3,17]$. All of our patients were treated with colchicine associated to steroids and immunosuppressors in 46 and $26.6 \%$ of cases, respectively. Corticosteroids and immunosuppressive agents like Cyclophasphamide are usually used for the management of cardiac lesions or if there is evidence of severe vascular manifestations. Thrombotic complications too may require immunosuppressors given that vascular inflammation plays a major role in thrombus formation. However treatment of arterial aneurysms remains challenging. Anticoagulant treatment should be administered cautiously with a close control in association to steroids and immunosuppressors given the risk of bleeding.

Surgical treatment may be problematic leading to pseudo aneurysms. Therefore surgical treatment should not be applied in the active phase of the disease [6].

The major limitation of our work is that it is a retrospective study especially faced to the incompleteness in data collection. It would be interesting to prospectively monitor how BD patients with predictive risk factors will evolve and how many will develop cardiac or vascular features.

\section{Conclusion}

Cardiac and vascular involvement in $\mathrm{BD}$ is frequent in the Tunisian context having sometimes threatening complications. It can occur during follow up or reveal the disease as the initial manifestation. Vascular manifestations are the most frequent affecting both veins and arteries. Deep venous thromboses are most common. Cardiac involvement can affect all layers ranging from pericarditis to intra cardiac thrombosis and myocardial infarction. We found that male gender is more prone to developing such complications in addition to patients presenting with erythema nodosum or neurologic involvement, needing therefore close monitoring. 
Management of cardiac and vascular involvement in Behçet disease is still lacking standardization as treatment is still based on a low level of evidence. Cardiologists should always be aware of such disease as they could be the first physicians to deal with the cardiac and vascular complications.

\section{Availability of data and materials}

The datasets used and/or analysed during the current study are available from the corresponding author on reasonable request.

\section{Authors' contributions}

MK: wrote the manuscript and done the bibliography research. SS: corrected the statistics. R. Kahloun: corrected the language and the final form of the manuscript. R. Klii, SH, and IK: participates with data. All authors read and approved the final manuscript.

\section{Ethics approval and consent to participate}

Not applicable.

\section{Consent for publication}

Not applicable.

\section{Competing interests}

The authors declare that they have no competing interests.

\section{Publisher's Note}

Springer Nature remains neutral with regard to jurisdictional claims in published maps and institutional affiliations.

\section{Author details}

'Internal Medicine and Endocrinology Department, Fattouma Bourguiba University Hospital, 1st June Avenue, 5000 Monastir, Tunisia. ${ }^{2}$ Physical Medicine and Rehabilitaion Department, Fattouma Bourguiba University Hospital, Monastir, Tunisia. ${ }^{3}$ Ophtalmology Department, Fattouma Bourguiba University Hospital, Monastir, Tunisia.

Received: 20 May 2018 Accepted: 31 August 2018

Published online: 01 October 2018

\section{References}

1. Alpsoy E. Behcet's disease: a comprehensive review with a focus on epidemiology, etiology and clinical features, and management of mucocutaneous lesions. J Dermatol. 2016;43:620-32.

2. International Study Group for Behçet's disease. Criteria for diagnosis of Behçet's disease. Lancet. 1990;335:1078-80.

3. Demirelli S, Degirmenci $\mathrm{H}$, Inci S, Arisoy A. Cardiac manifestations in Behcet's disease. Intractable Rare Dis Res. 2015:4(2):70-75.

4. B'chir Hamzaoui S, Harmel A, Bouslama K, Abdallah M, Ennafaa M, M'rad S, le groupe tunisien d'étude Sur la maladie de Behçet, et al. Behçet's disease in Tunisia. Clinical study of 519 cases. La Revue de médecine interne. 2006 27:742-50.

5. Geri G, Wechsler B, Thi Huong du L, Isnard R, Piette JC, Amoura Z, et al. Spectrum of cardiac lesions in Behçet disease. A series of 52 patients and review of the literature. Medicine. 2012;91:25-34.

6. Fei $Y, L i X$, Lin S, Song X, Wu Q, Zhu Y, et al. Major vascular involvement in Behçet's disease: a retrospective study of 796 patients. Clin Rheumatol. 2013;32:845-52.

7. Bang D, Lee JH, Lee ES, Lee S, Choi JS, Kim YK, et al. Epidemiologic and clinical survey of Behcet's disease in Korea: the first multicenter study. J Korean Med Sci. 2001;16(5):615-8

8. Sakane T, Takeno M, Suzuki N, Inaba G. Behçet's disease. Engl J Med. 1999; 341(17):1284-91.

9. Bono W, Filali-Ansary N, Mohattane A, Tazi-Mezalek Z, Adnaoui M, Aouni M, et al. Cardiac and pulmonary artery manifestations during Behcet's disease. Rev Med Interne. 2000;21:905-7.

10. Fekih M, Fennira S, Ghodbane L, Zaouali RM. Intracardiac thrombosis: unusual complication of Behcet's disease. Tunis Med. 2004;82:785-90.
11. Darie $C$, Knezinsky M, Demolombe-Rague $S$, Pinède $L$, Périnetti $M$, Ninet JF, et al. Cardiac pseudotumor revealing Behcet's disease. Rev Med Interne. 2005;26:420-4

12. Lakhanpal S, Tani K, Lie JT, Katoh K, Ishigatsubo Y, Ohokubo T. Pathologic features of Behcet's syndrome: a review of Japanese autopsy registry data. Hum Pathol. 1985;16:790-5.

13. Ma WG, Zheng J, Zhu JM, Liu YM, Li M, Sun LZ. Aortic regurgitation caused by Behcet's disease: surgical experience during an 11-year period. J Card Surg. 2012;27:39-44.

14. Tohmé A, Aoun N, El-Rassi B, Ghayad E. Vascular manifestations of Behcet's disease. Eighteen cases among 140 patients. Joint Bone Spine. 2003:70:384-9.

15. Jambeih R, Salem G, Huard DR, Jones KR, Awab A. Hughes Stovin syndrome presenting with hematuria. Am J Med Sci. 2015;(5):425-6.

16. Balci NC, Semelka RC, Noone TC, Worawattanakul S. Multiple pulmonary aneurysms secondary to Hughes-Stovin syndrome: demonstration by MR angiography. J Magn Reson Imaging. 1998;(6):1323-5.

17. Hatemi G, Silman A, Bang D, Bodaghi B, Chamberlain AM, Gul A, et al. EULAR recommendations for the management of Behcet disease. Ann Rheum Dis. 2008;67:1656-62.

\section{Ready to submit your research? Choose BMC and benefit from:}

- fast, convenient online submission

- thorough peer review by experienced researchers in your field

- rapid publication on acceptance

- support for research data, including large and complex data types

- gold Open Access which fosters wider collaboration and increased citations

- maximum visibility for your research: over $100 \mathrm{M}$ website views per year

At BMC, research is always in progress.

Learn more biomedcentral.com/submissions 